\title{
Numerical Simulation of Non-Adiabatic Capillary Tubes. Special Emphasis on the Near-Saturation Zone
}

\author{
Nicolás Ablanque, Carles Oliet, Joaquim Rigola, Assensi Oliva \\ Universitat Politècnica de Catalunya - BarcelonaTech (UPC), Heat and Mass Transfer \\ Technological Centre (CTTC), Terrassa, Barcelona, Spain
}

\begin{abstract}
The aim of this article is to present a distributed numerical model that simulates the thermal and fluid-dynamic phenomena inside non-adiabatic capillary tubes. The resolution approach is based on a two-phase flow model where the fluid domain is discretized in a one-dimensional way, and the governing equations (continuity, momentum, and energy) are solved by means of a step-by-step algorithm. The model explained herein consists of an improved and extended version of previous works (Escanes et al., 1995, García-Valladares et al., 2002a) b, Ablanque et al. 2010) including two additional features. On the one hand, it allows the simulation of the two typical geometric arrangements found in capillary-tube/suction-line heat exchangers (i.e. concentric and lateral). On the other hand, it has an enhanced capability to address the convergence difficulties found in distributed models at the near-saturation zone. This document presents the major numerical adaptations done to the model, a comprehensive validation of the two geometric configurations, the model performance when tackling the aforementioned numerical difficulties and finally, some numerical studies.

Keywords: Refrigeration, Expansion device, Capillary tube, Two-phase flow, Convergence, Numerical model
\end{abstract}

\section{Introduction}

A capillary tube is an expansion device commonly used in small refrigerating and air-conditioning systems. It connects the condenser/gas-cooler to the 
evaporator, and its main role is to regulate the refrigerant flow according to the system needs. In general, a capillary tube does not works as efficiently over a wide range of operating conditions (i.e. heat load, ambient temperature, refrigerant charge) as does a thermostatic expansion valve. However, it is reliable, less 5 expensive, and performs nearly as well. It also reduces the compressor starting torque as the whole system pressure equalizes when the compressor is switched off.

A typical capillary tube consists of a small-bore tube with a fixed length. It is common practice to solder the capillary tube on the compressor suction line (or alternatively to place a portion of the capillary tube inside the suction line) so that heat is transferred from the former to the latter in order to increase the system capacity, and also to prevent liquid from entering the compressor. This type of arrangement is called a capillary-tube/suction-line heat exchanger (see Figures 1 and 2). Despite the capillary tube simple geometry, the fluid-dynamic and thermal phenomena occurring inside are very complex (phase transitions, non-equilibrium effects, heat transfer, compressibility).

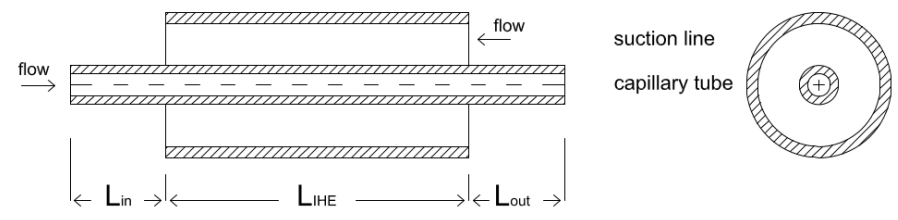

Figure 1: Capillary-tube/suction-line heat exchanger: concentric configuration.

An accurate design of such devices is required to optimize the whole system performance. In the latest decades several numerical models and experimental studies for adiabatic and non-adiabatic capillary tubes have been presented in the technical literature as reported by Khan et al. (2009a). The proposed numerical models are usually based on two different approaches: correlationbased models or distributed parameter models. The correlation-based models consist of mathematical equations fitted from experimental data, but lacking 

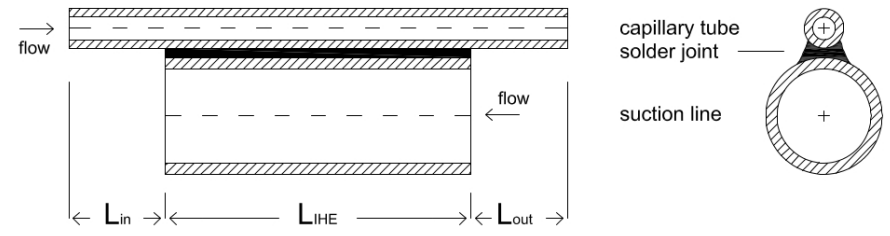

Figure 2: Capillary-tube/suction-line heat exchanger: lateral configuration.

strong physical foundations, e.g., Sarker and Jeong (2012). Their response is instantaneous, but they are usually refrigerant-dependent and have a questionable out-of-range reliability. In the distributed parameter models, the domain is divided in several control volumes where the governing equations (continu5 ity, momentum, and energy) are solved, e.g., Escanes et al. (1995) and Bansal and Yang (2005). This type of models consumes more computational time with respect to the correlation-based models but provides higher level of detail and greater adaptability to different geometric and operating conditions. This latter approach is more worthy to investigate from a research point of view Qiao 10 et al. 2010.

It has been observed that the distributed parameter models present convergence issues in non-adiabatic capillary tubes due to flow discontinuities caused by the re-condensation of the refrigerant within the heat exchange section. For instance, the distributed model described by Negrão and Melo (1999) was found to be conditionally convergent (complete convergence was not attainable in cases where the refrigerant flow pressure approached the saturation limit with a similar slope). The authors suggested to extrapolate results in order to predict non-convergent cases. Similar numerical problems were detected in the model proposed by Bansal and Xu (2003). In this case, the authors realized that their model experienced convergence instabilities when re-condensation occurred in capillary tubes with relatively short outlet adiabatic sections. If the refrigerant entered the outlet adiabatic section as subcooled liquid, their model needed a relatively long section to reach the critical state. To the best of the present paper 
authors' knowledge, this particular problem has only been tackled by Hermes et al. (2008) where simplifying assumptions were considered in order to avoid convergence difficulties, e.g., uniform heat flux and prescribed heat exchanger effectiveness. A model with reduced time response was achieved, but to the 5 detriment of the suction line fluid simulation accuracy and level of detail.

The potential of the detailed one-dimensional distributed model initially develpped by Escanes et al. (1995) has been studied in the works by García-Valladares et al. (2002a b) where non-adiabatic and metastable effects have been analyzed. The same methodology has been used by Ablanque et al. (2010) to conduct a parametric study on typical capillary tubes used in household refrigerators working with isobutane. The model has been internally tested by the present authors at the unstable geometric and operating ranges reported by other authors and, as expected, similar convergence problems were occurring. Therefore, a painstaking revision of the model mathematical resolution procedure has been carried out in order to address these difficulties and also to understand the nature of the convergence instabilities apparently inherent to distributed models. The outcome of the latter revision is reflected in this document, which is focused on reviewing the major changes and modifications that have greatly improved the model convergence stability.

20 The present article is structured in four main sections. Firstly, a section devoted to briefly explain the general formulation and the resolution procedure of the former model version (Ablanque et al. 2010), and to provide a detailed description of the new algorithm enhanced resolution methodology. Secondly, a section presenting a comprehensive experimental validation of the new capillarytube/suction-line heat exchangers model. Thirdly, a section focused on showing the performance of the enhanced model at the most challenging convergence conditions reported by other authors. And fourthly, a section with numerical studies carried out with the enhanced model; namely the influence of the inlet operating parameters, the influence of the geometric arrangement type, and an 30 analysis of the heat transfer between the capillary tube and the suction line. 


\section{Numerical Model}

The non-adiabatic capillary tube resolution combines a quasi-homogeneous two-phase flow model and an iterative procedure to calculate the critical conditions. In this section the detailed description of the former numerical model

5 (formulation and resolution) is provided together with the specific numerical aspects that have been modified to improve the model convergence.

\subsection{Mathematical Formulation}

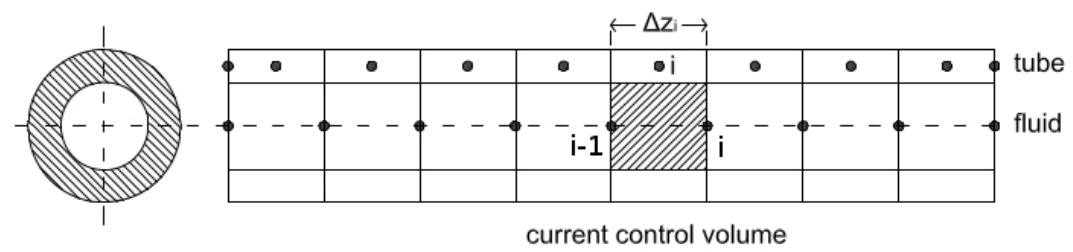

Figure 3: Tube discretization scheme (fluid and solid).

The fluid flow domain inside tubes is discretized in a one-dimensional form as shown in Figure 3 A multi-dimensional approach will greatly increase the computational cost and make difficult to succesfully solve a complex system such as a non-adiabatic capillary tube (although physically simple, several phenomenological aspects are present: heat transfer, phase change, non-equilibrium, and sonic effects). The discretization consists of series of control volumes (placed consecutively between the tube inlet and outlet cross-sections) and nodes (placed at the control volumes inlet and outlet cross-sections). The steady-state two-phase flow conservative equations of mass, momentum, and energy are integrated along the flow domain and expressed as follows:

$$
\begin{gathered}
\dot{m}_{i}-\dot{m}_{i-1}=0 \\
\dot{m}_{i} v_{i}-\dot{m}_{i-1} v_{i-1}=\left(p_{i-1}-p_{i}\right) S-\bar{\tau} \pi D \Delta z_{i}-\rho_{c v}^{-} g \sin (\theta) S \Delta z_{i}
\end{gathered}
$$




$$
\dot{m}_{i}\left(h_{i}+e_{c, i}+e_{p, i}\right)-\dot{m}_{i-1}\left(h_{i-1}+e_{c, i-1}+e_{p, i-1}\right)=\dot{q}_{c v}^{-} \pi D \Delta z_{i}
$$

The two-phase flow model has a quasi-homogeneous approach as only the mean properties are defined at nodes, but different velocities are considered for the gas and liquid phases. The full development of the conservative equations is reported in Ablanque (2010). The whole domain is solved on the basis of 5 a step-by-step numerical scheme. The equations are rearranged and solved for the downstream position (i.e. from the duct flow inlet conditions; namely, pressure, enthalpy, and mass flow rate, each control volume outlet state is calculated sequentially). The formulation requires the use of appropriate empirical correlations to evaluate three specific parameters: the gas void fraction which is used to calculate the two-phase flow mean density (Premoli et al., 1970), the heat transfer coefficient which is used to predict the heat transferred between the fluid and the solid tube (Gnielinski 1976 for in-tube single-phase flow, Wiegand et al.|1945 for annular single-phase flow, Gungor and Winterton 1987 for in-tube evaporation, and Shah 1979 for in-tube condensation), and the shear stress which is used to calculate the force due to friction (Churchill, 1977, Friedel, 1979). The fluid properties were obtained from the database NIST (2002).

It is worth mentioning that a metastable phenomenon takes place inside capillary tubes when the refrigerant changes from subcooled to liquid-vapor twophase mixture (the vaporization does not occur at the location of thermodynamic saturated state but somewhere downstream from the saturation point). ${ }_{\square}$ To the best of the present work authors' knowledge only the correlation of Chen et al. (1990) is available in the open literature to predict the vaporization delay.

However, this correlation has been developed for adiabatic capillary tubes working with R-12 and was proved to be inappropriate for non-adiabatic capillary tubes (Melo et al. 1999). Therefore, the metastable phenomenon has not been considered in this particular study. 


\subsection{Solution Methodology}

The mass flow rate inside a capillary tube increases as the discharge pressure decreases, but only up to a critical value from which the mass flow rate remains constant. This limit is called the choked flow condition and occurs when the 5 refrigerant reaches the sonic velocity at the exit of the tube. At this point, the maximum mass flow rate for the selected tube diameter is attained as the fluid velocity can not exceed the velocity of sound. A capillary tube is typically designed to operate at the critical condition so that the goal of any numerical model is to accurately predict it. The choked condition can be numerically predicted when the entropy generation equation is no longer accomplished (i.e. $\dot{s}_{g e n, i}<0$ ) or alternatively as the pressure gradient (i.e. $d p / d z$ ) approaches to infinity. The latter condition can also be expressed as $d z / d p<\epsilon$. The numerical calculation of the two-phase flow can not proceed any further when the choked condition is attained. Therefore, the global resolution procedure is carried out iteratively so that the mass flow rate entailing a choked flow condition at the exit of the tube can be found (see Figure 47. The obtained value represents the critical mass flow rate of the simulated capillary tube. It is worth mentioning that in order to appropriately find the choked condition at the end of the tube, it is convenient to use a non-uniform 20 grid for the fluid domain discretization due to the high pressure gradients produced. Furthermore, the resolution algorithm includes an optional additional loop to ensure that the refrigerant mass flow rate through the capillary tube is equal to that of the suction line.

The capillary-tube/suction-line heat exchanger is divided in three sections (adiabatic inlet section, non-adiabatic intermediate section and adiabatic outlet section) which are calculated sequentially as observed in the scheme from Figure 4 . The calculation of the non-adiabatic section of the capillary-tube/suctionline heat exchanger includes the flow through the suction line, as well as the energy balance over the solid parts. This particular section is modeled differently according to the selected geometric arrangement. A concentric non-adiabatic 


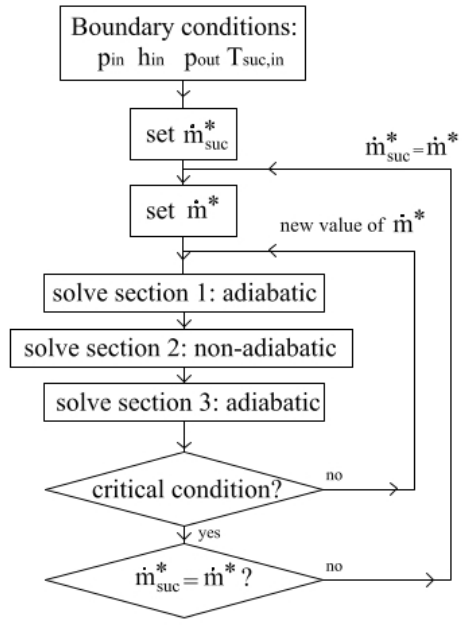

Figure 4: Capillary tube: former resolution scheme (Ablanque et al. 2010).

section is made up of four domains; namely, the fluid flow through the capillary tube (circular cross-section), the fluid flow through the suction line (annular cross-section), the inner tube, and the outer tube. Conversely, a lateral nonadiabatic section consists of three domains; namely, the fluid flow through the 5 capillary tube (circular cross-section), the fluid flow through the suction line (circular cross-section), and a unique solid domain which represents both the capillary and the suction line tubes. The process of solving the non-adiabatic section is carried out in a segregated way where the corresponding domains are solved iteratively until a converged solution is obtained.

\subsection{Convergence Improvement: Numerical Aspects}

The model described so far presents similar convergence difficulties when compared to other distributed models that have dealt with operating conditions and geometric arrangements leading to instabilities (Negrão and Melo, 1999 and Bansal and $\mathrm{Xu}, 2003)$. In fact, many other distributed models reported in the

15 technical literature have not tackled such challenging conditions. Therefore, a meticulous analysis of the present model has been carried out in order to address 
these issues. The model has been subjected to a full set of modifications to improve its convergence sturdiness. The aim of these modifications was to soften all possible kind of discontinuities entailing convergence instabilities. They are described in detail in the following paragraphs.

- Resolution methodology. The new numerical resolution procedure is carried out differently as the critical condition of the capillary tube is calculated at the end of every solid temperature map iteration (see Figure 5). Consequently, more internal iterations are carried out but the method stability is improved as the critical condition is always predicted for a well defined solid temperature map. This procedure avoids the full calculation of the non-adiabatic section at every intermediate iteration of the mass flow rate. Therefore, it prevents unexpected choked flow inside the heat exchanger section from occurring (see Figure 4).

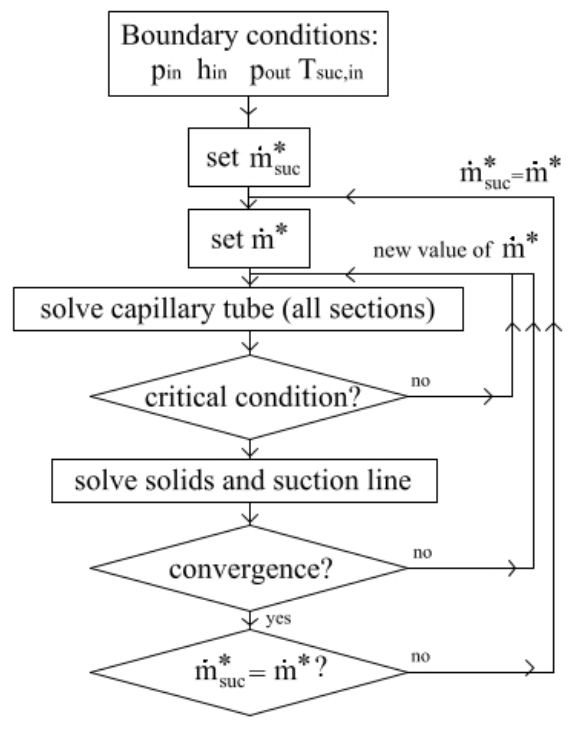

Figure 5: Capillary tube: new resolution scheme.

- Common non-uniform grid. In the former version the capillary-tube/suctionline heat exchanger was divided into three sections. The first two sections 
had an even control volume distribution, while the non-uniform distribution was only used in the outlet adiabatic section. The new model considers a common non-uniform grid for the whole domain so that the size of control volumes changes progressively from one end to the other. This approach prevents two consecutive control volumes from having a very different length.

- Phase transitions. It has been observed that the calculated heat transfer coefficient values presented significant leaps in transitional zones, e.g., from two-phase to single-phase during the re-condensation phenomenon. Two important considerations have been implemented to reduce the impact of such discontinuities. Firstly, the sudden change in the use of one type of correlation to another has been softened by calculating adequate interpolated transitional values. And secondly, a control volume where a phase transition occurs has now a special treatment (the control volume is divided into two smaller parts by finding the exact location of the phase boundary so that each part uses the most appropriate correlation).

- Axial heat transfer. The new model takes into account the heat transfer between the refrigerant fluid and the solid tube along the whole capillary tube (i.e. including both the inlet and the outlet adiabatic sections). This new feature allows having a smooth axial tube temperature variation throughout the whole solid tube.

\section{Model Validation}

The enhanced numerical model for capillary-tube/suction-line heat exchangers detailed in the previous section is evaluated against experimental data found in the technical literature. The information available for non-adiabatic capillary tubes is scarce in comparison to adiabatic straight capillary tubes. However, valuable data have been gathered in order to achieve a comprehensive validation of the present model. The experimental studies used for this purpose are summarized in Table 1 . The selected data include different refrigerants and the two 
typical arrangement types. A total of 278 experimental tests were used for the present comparison (203 tests for the lateral arrangement and 75 for the concentric one). A preliminary validation has already been presented in Ablanque et al. (2014).

5 Dirik et al. (1994) carried out a numerical and experimental study on adiabatic and non-adiabatic capillary tubes working with R-134a. As regards to the non-adiabatic cases, a total of 63 experimental tests were conducted on a capillary-tube/suction-line heat exchanger with concentric arrangement. The tests were carried out at three different condensing pressures, a capillary tube inlet subcooling degree ranging from 5 to $20{ }^{\circ} \mathrm{C}$, and considering two inner diameter sizes as well as two capillary tube lengths. Despite the large number of experimental tests, only 12 runs were reported with sufficient information to be simulated with the present model (the most relevant operating parameters were available except for the suction line outlet temperature).

Greenfield and Dunn (1994) reported data for non-adiabatic flow of R-134a in a capillary-tube/suction-line heat exchanger of the lateral arrangement type. The tests were carried out with a fixed geometry but, varying the capillary tube inlet conditions (three inlet pressures and three different subcooling degrees were considered). The operating and geometric characteristics were reported in detail for 7 different runs. The wall roughness value was not specified so that a typical value for smooth tubes is used for the present simulations.

Peixoto (1995) has performed several experimental tests on non-adiabatic capillary tubes with both concentric and lateral configurations. The capillary tube operating parameters have been studied but, the geometric characteristics have been kept constant (except for the arrangement type). For each geometric arrangement two different condensing pressures were evaluated for a wide range of subcooling values (and a specific inlet suction line temperature value was considered for each condensing pressure value). No information was presented for the suction line outlet temperature. A total of 10 and 23 experimental tests 30 were reported in detail for the lateral and concentric arrangements, respectively. 
Mendonça et al. (1998) experimentally evaluated the performance of lateral capillary-tube/suction-line heat exchangers over a wide application range typical of household refrigerators and freezers working with R-134a. The measured mass flow rate was reported for 23 tests, from which 7 tests also included the 5 fluid temperature profile along the suction line together with the capillary tube wall temperature distribution. The tests were carried out considering two different pressures, two different capillary tube diameters, two different suction line diameters, and various heat exchange section relative positions and lengths. It should be noticed that the experimental tests conducted at the smaller diameter were not considered for the present validation due to reported uncertainties on the inner diameter measurements as commented by García-Valladares (2007). Therefore, only 11 runs are reproduced with the present model.

Melo et al. (2000) carried out an experimental study on non-adiabatic flow of R-134a through capillary tubes. The test rig consisted of a concentric capillarytube/suction-line heat exchanger. Temperature measurements of the suction line fluid as well as both the capillary tube and the suction line walls were taken throughout the whole capillary tube length. A total of 12 cases were reported with different operating conditions and geometric characteristics. For the present comparison all but two cases are included as the infomation given for these two cases presented disagreement.

Melo et al. (2002) conducted a complete experimental study on concentric capillary-tube/suction-line heat exchangers working with R-600a. The refrigerant mass flow rate together with the suction line outlet temperature were reported for each test. In their experimental investigation the effect of various operating and geometric parameters was evaluated; namely, the inlet pressure, the subcooling degree, the capillary tube inner diameter, the suction line inlet temperature, the suction line inner diameter, the total length, and the distribution of the adiabatic/non-adiabatic sections along the capillary tube. Empirical correlations to predict the mass flow rate and the suction line outlet temperature were developed based on the resulting database. A total of 30 experimental cases are compared against the present model predictions. 

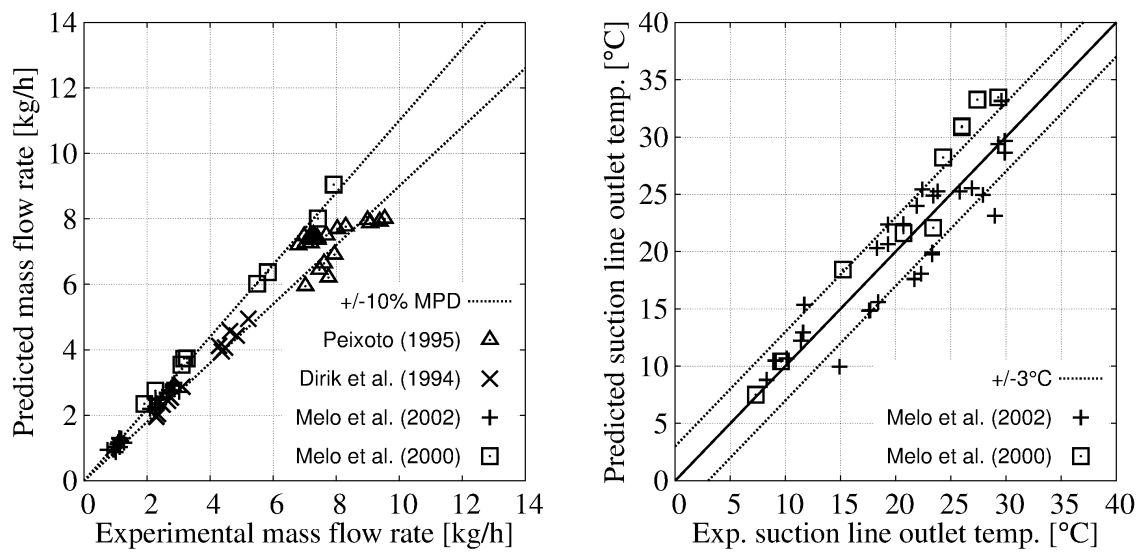

Figure 6: Scatter diagram between the numerical model predictions and the experimental data for the concentric arrangement: mass flow rate (left) and suction line outlet temperature (right).

Wolf and Pate (2002) carried out an experimental study for lateral nonadiabatic capillary tubes where a wide variety of operating and geometric conditions was considered as well as five different refrigerants (R-134a, R-22, R-410A, R600a and R-152a). The wall roughness value was not specified and, therefore, 5 a typical value for smooth tubes is used for the present simulations. A total of 150 experimental tests, including three different refrigerants, are simulated with the present model.

Khan et al. (2009b) presented a comprehensive experimental investigation on adiabatic and non-adiabatic capillary tubes working with R-134a and proposed empirical correlations to predict the mass flow rate. The setup for the nonadiabatic cases consisted of a lateral counter-flow geometric arrangement where the effects of the tube diameter, the tube length and the subcooling degree were studied. A total of 25 tests, all conducted with the same capillary tube diameter, are compared with the present model simulations.

Figures 6 and 7 show the present model results compared with the experimental data for the concentric and lateral arrangements, respectively. The 

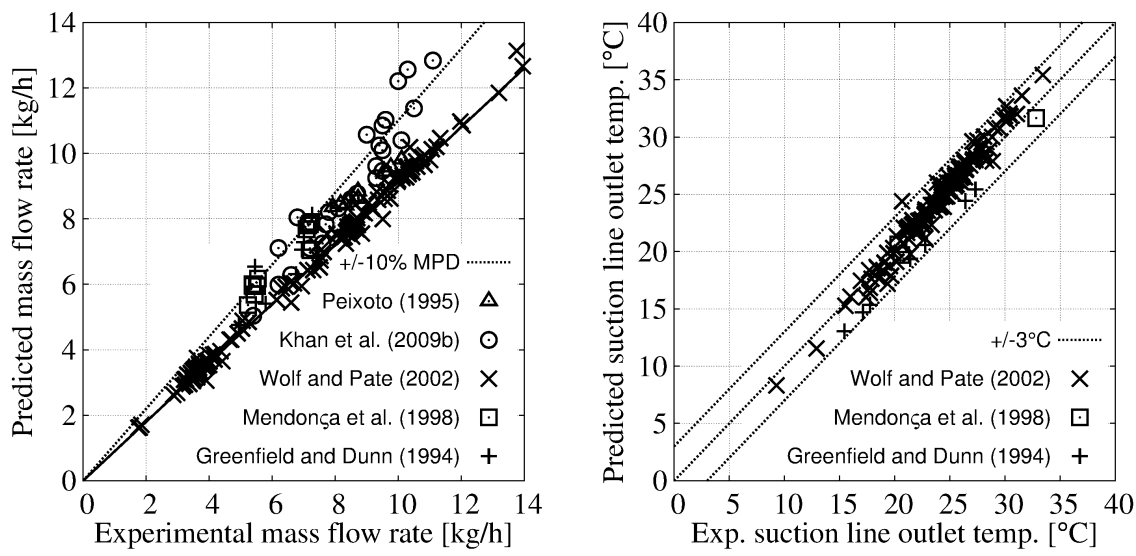

Figure 7: Scatter diagram between the numerical model predictions and the experimental data for the lateral arrangement: mass flow rate (left) and suction line outlet temperature (right).

overall mean prediction deviation $\left(M P D=(1 / N) \sum_{i=1}^{N}\left(\left|\phi_{\text {exp }}-\phi_{\text {calc }}\right| / \phi_{\text {exp }}\right)_{i}\right)$ for the mass flow rate is $8.1 \%$. In general, the numerical model has a reasonably good accuracy when predicting the mass flow rate as more than $75 \%$ of the data falls within a discrepancy of $+/-10 \%$. A similar degree of accuracy is attained 5 by other distributed numerical models, e.g., Hermes et al., 2008. The agreement for the suction line outlet temperature prediction is also acceptable as the mean relative temperature deviation $\left(M R T D=(1 / N) \sum_{i=1}^{N}\left(\mid T_{\text {suc, out }, \text { exp }}-\right.\right.$ $\left.\left.T_{\text {suc,out }, \text { calc }} \mid /\left(T_{\text {suc,out }, \text { exp }}-T_{\text {suc,in,exp }}\right)\right)_{i}\right)$ is $4.4 \%$. These discrepancies may be partially due to all the possible experimental uncertainties (measurements, capillary tube inner diameter, wall roughness value, etc.), to the intrinsic deviation of the selected empirical correlations, and also to the lack of the metastable phenomenon prediction.

The detailed temperature profiles through non-adiabatic capillary tubes was experimentally investigated in the works by Mendonça et al. (1998) and Melo et al. (2000) for lateral and concentric configurations, respectively. The fluid temperature distribution along the suction line together with the capillary tube 


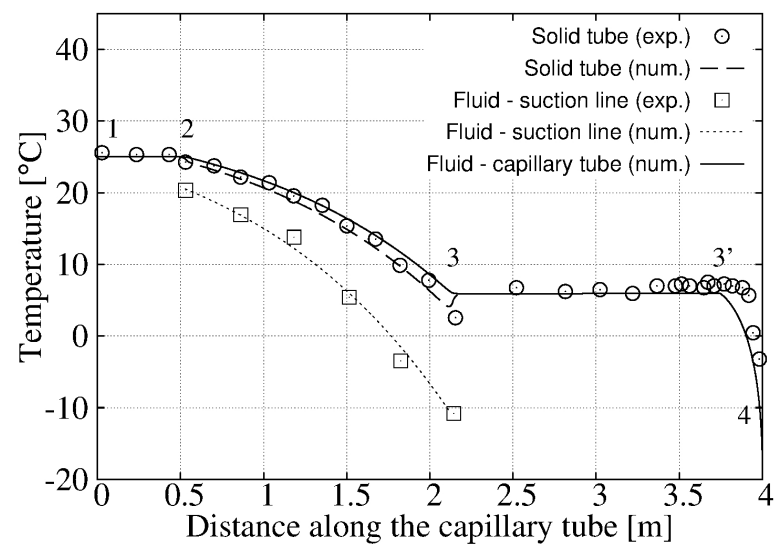

Figure 8: Measured vs. predicted temperature profiles along a lateral arrangement capillarytube/suction line heat exchanger. Experimental data from Mendonça et al. (1998) (D = 0.83 $\mathrm{mm}, \mathrm{D}_{\text {suc }}=4.8 \mathrm{~mm}, \mathrm{p}_{\text {cond }}=9 \mathrm{bar}, \Delta \mathrm{T}_{\text {sub }}=10.5{ }^{\circ} \mathrm{C}, \mathrm{p}_{\text {evap }}=-17.6{ }^{\circ} \mathrm{C}, \mathrm{T}_{\text {suc }, \text { in }}=-11.1$ $\left.{ }^{\circ} \mathrm{C}\right)$.

wall temperature distribution were measured for several cases. No distinction was made between the capillary tube wall and the refrigerant temperatures due to the high convective heat transfer coefficient on the capillary tube side. The predictions conducted with the present model are compared against two particu5 lar cases, as shown in Figures 8 and 9 for lateral and concentric configurations, respectively. Figure 8 includes numbers along the temperature profile which indicate the sections inlet and outlet positions: inlet adiabatic section (1-2), heat exchanger section (2-3), and outlet adiabatic section (3-4). The refrigerant changes from liquid to two-phase state in position 3'. A general agreement is obtained for both the suction line temperature and the wall temperature profiles. Furthermore, the wall temperature dips observed at the two limits between adiabatic and non-adiabatic sections are qualitatively well reproduced by the model. 


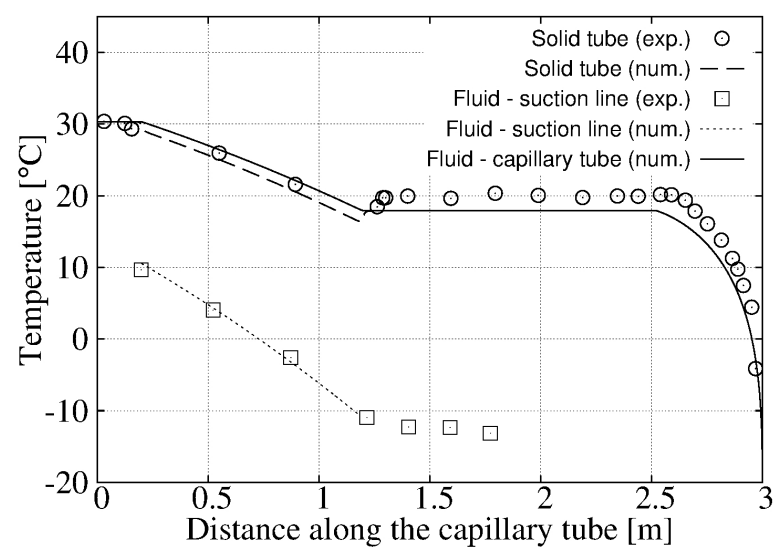

Figure 9: Measured vs. predicted temperature profiles along a concentric arrangement capillary-tube/suction line heat exchanger. Experimental data from Melo et al. (2000) (D $=0.83 \mathrm{~mm}, \mathrm{D}_{\text {suc }}=7.86 \mathrm{~mm}, \mathrm{p}_{\text {cond }}=9 \mathrm{bar}, \Delta \mathrm{T}_{\text {sub }}=5.2{ }^{\circ} \mathrm{C}, \mathrm{p}_{\text {evap }}=-23.1^{\circ} \mathrm{C}, \mathrm{T}_{\text {suc, in }}=$ $\left.-11.0^{\circ} \mathrm{C}\right)$.

\section{Near-Saturation Zone Analysis}

The distributed models proposed in the technical literature have reported convergence instabilities at particular geometric and operating conditions in non-adiabatic capillary tubes, e.g., Negrão and Melo, 1999 and Bansal and Yang,

5 2005. The numerical problem occurring at such situations can be studied from an illustrative case carried out with the former model version Ablanque et al. 2010) where the convergence is not reached. The case consists of a concentric capillary-tube/suction-line heat exchanger working with R-600a, inner diameter $0.553 \mathrm{~mm}$, total length $3.4 \mathrm{~m}$, inlet adiabatic section length $0.6 \mathrm{~m}$, and heat 10 exchange section length $2.2 \mathrm{~m}$. The results are depicted in Figure 10 .

At a specific point during the iteration process the numerical model is not able to find the appropriate mass flow rate that entails a choked flow at the exit of the capillary tube. In fact, for a very slight variation of the mass flow rate value, the simulation result goes from a case where no choked flow condition is attained (Case a) to a case where the choked flow occurs inside the heat exchange section (Case b), and consequently, the numerical calculations can not 

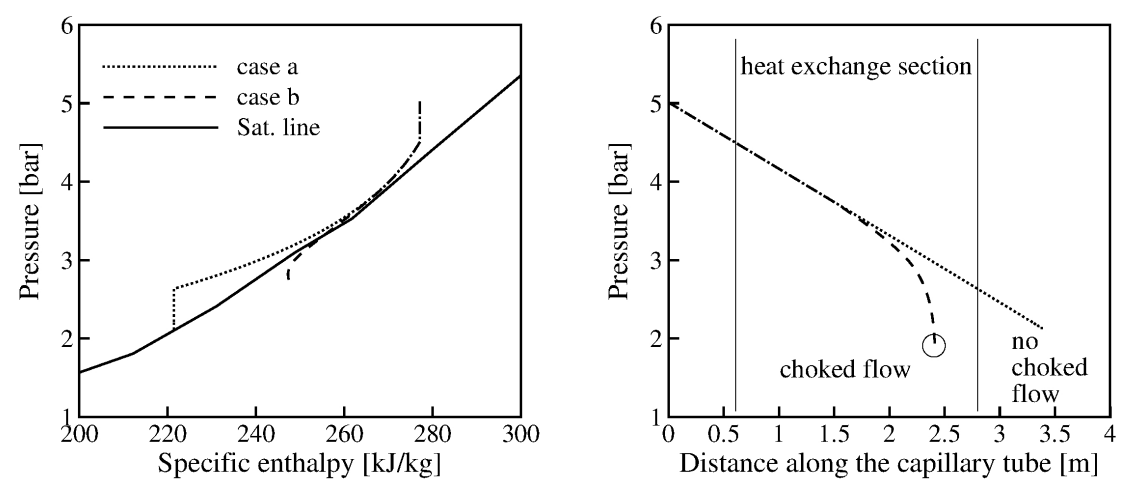

Figure 10: Pressure profiles of a non-convergent situation (Case a, mass flow rate $0.954 \mathrm{e}-4 \mathrm{~kg}$ $\mathrm{h}^{-1}$, and Case b, mass flow rate $\left.0.954+1 \mathrm{e}-11 \mathrm{~kg} \mathrm{~h}^{-1}\right)$.

proceed any further. What happens is that, when the refrigerant pressure slope equals the refrigerant saturation pressure slope, the numerical model faces a critical situation. The model will consider the refrigerant pressure slope to be either lower (Case a) or higher (Case b). The former situation (Case a) leads to 5 a full re-condensation of the refrigerant and a high degree of subcooling. The refrigerant pressure will keep dropping linearly so that the choked flow condition at the exit is unreachable. The latter situation (Case b) will result on a pressure drop acceleration leading to a choked flow inside the heat exchange section. If the wrong path is chosen by the numerical code, the iterative procedure will probably diverge and be unable to find the choked flow at the exit of the tube. This unwanted situation could be reversed by modifying the capillary tube geometry (e.g. by extending the outlet adiabatic section) and/or modifying its operating conditions (e.g. by reducing the heat transfer or increasing the inlet degree of subcooling).

${ }_{15}$ This divergence problem has been carefully addressed and several modifications have been done to the capillary tube model (see Section 2.3p. In the following paragraphs, the enhanced numerical model is used to predict the capillary tube thermal and fluid-dynamic behaviour at the aforementioned challenging condi- 
tions and compared against other distributed models (a preliminary study was already reported in Ablanque et al., 2014.

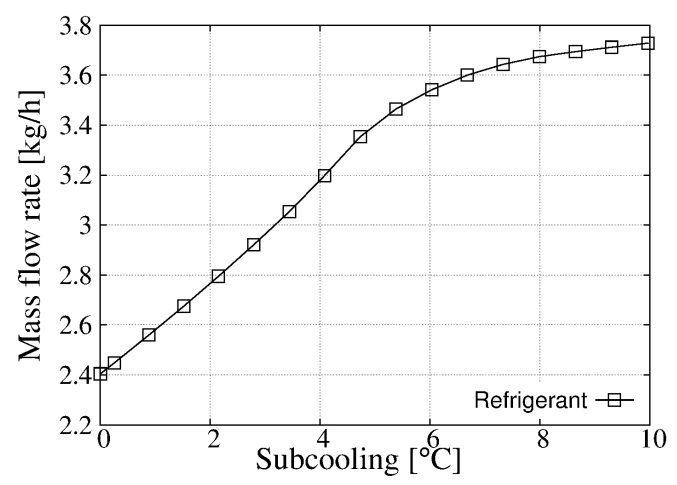

Figure 11: Present model predictions of the numerical study reported in Negrão and Melo (1999).

\subsection{Simulations of Negrão and Melo}

Negrão and Melo (1999) carried out a numerical simulation on a concentric 5 capillary-tube/suction-line heat exchanger with R-134a. The following geometric conditions were considered: total length $3 \mathrm{~m}$, inlet section length $0.6 \mathrm{~m}$, heat exchanger length $2.2 \mathrm{~m}$, capillary tube inner diameter $0.61 \mathrm{~mm}$, wall roughness $2.13 \mu \mathrm{m}$, and suction line inner diameter $7.86 \mathrm{~mm}$. The operating conditions were: inlet pressure $13.99 \mathrm{kPa}$, evaporating temperature $-22.9{ }^{\circ} \mathrm{C}$, suction line inlet temperature $-11.2{ }^{\circ} \mathrm{C}$, and subcooling ranging from 0 to $10^{\circ} \mathrm{C}$. Their investigation revealed that convergence could not be found in the subcooling range from 3.9 to $5.8^{\circ} \mathrm{C}$.

Figure 11 shows that convergence was possible throughout the whole proposed subcooling range with the present numerical model. In order to understand and visualize the cause of the convergence issues occurring within the subcooling range from 3.9 to $5.8^{\circ} \mathrm{C}$, the results of the specific case obtained at $4.75{ }^{\circ} \mathrm{C}$ of subcooling is studied in detail in Figures 12 and 13 .

Figure 12 shows the pressure, temperature, gas weight fraction, and heat 

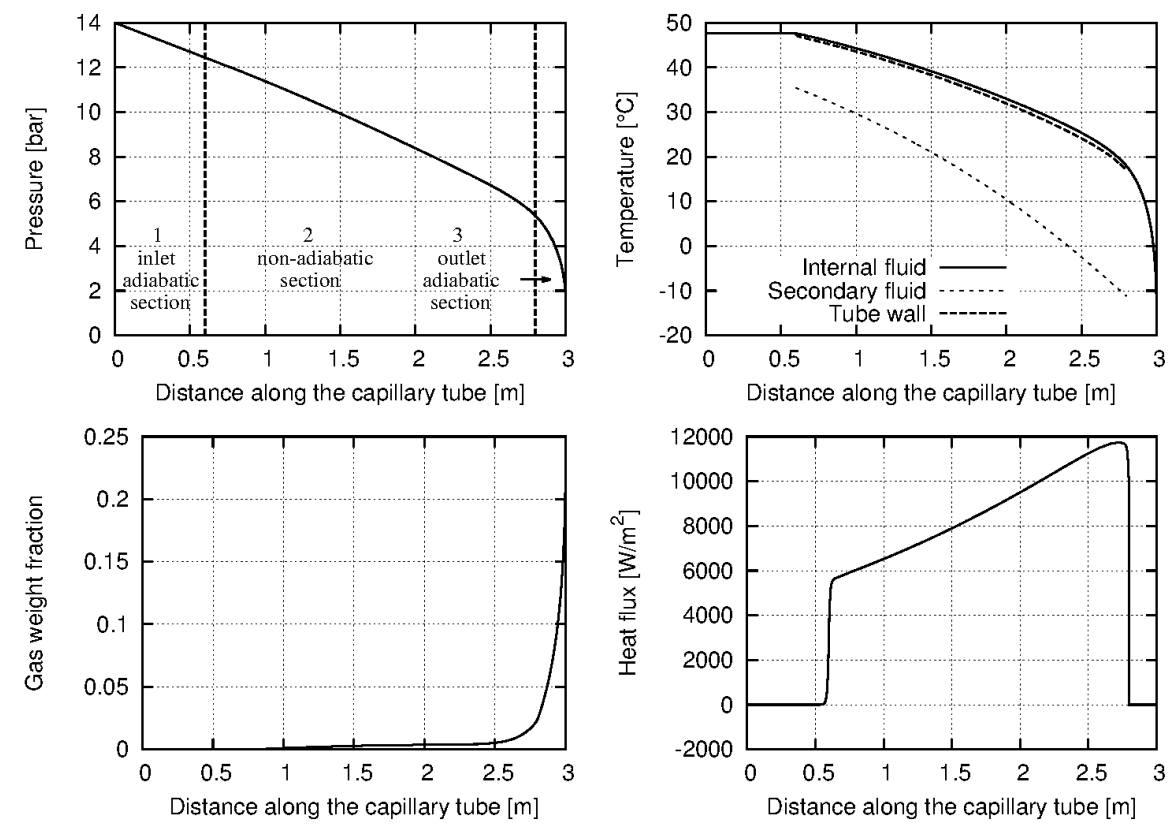

Figure 12: Profiles of refrigerant parameters for non-adiabatic capillary tube. Concentric configuration. Subcooling $4.75{ }^{\circ} \mathrm{C}$.

transfer evolution of the refrigerant along the capillary tube. The temperature and pressure profiles suggest that the typical steep decrease of pressure at the outlet adiabatic section of the capillary tube starts inside the heat exchanger section. The weight fraction profile indicates that no full re-condensation phe5 nomenon is occurring in this case (i.e. when the refrigerant flow changes from two-phase to single-phase condition). The smooth heat flux profile illustrates the effect of the implementations done to the model that prevent thermal discontinuities from happening (see Section 2.3). The evolution of the refrigerant flow through the capillary tube on a pressure vs. enthalpy diagram is plotted in

${ }_{10}$ Figure 13. It is clearly observed that the refrigerant pressure curve follows almost the same path as the saturation line for a long distance. This aspect leads to a very unstable situation where the convergence of most distributed models could be seriously affected. Therefore, the possibility to achieve convergence 


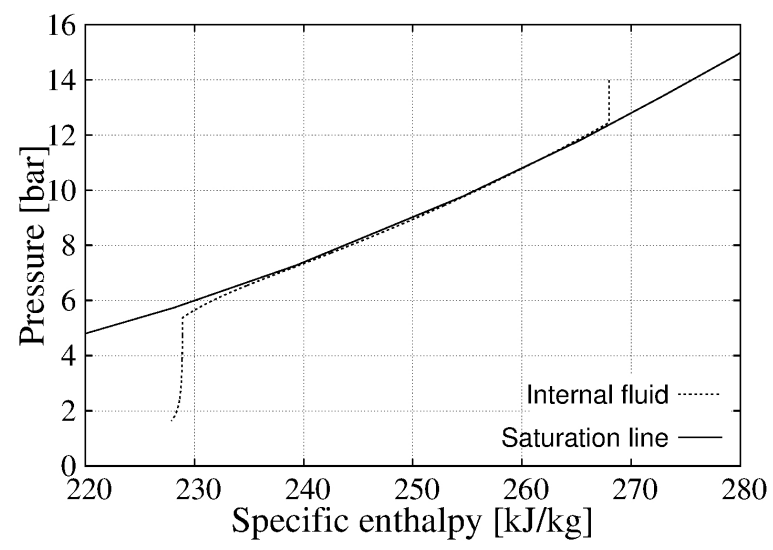

Figure 13: Pressure vs. specific enthalpy diagram for non-adiabatic capillary tube. Concentric configuration. Subcooling $4.75^{\circ} \mathrm{C}$.

relies on a very meticulous numerical treatment.

Negrão and Melo (1999) have also carried out a numerical simulation on a lateral capillary-tube/suction-line heat exchanger with R-134a and have also reported convergence issues. That case has been succesfully reproduced with

5 the present model and similar conclusions were drawn.

\subsection{Simulations of Bansal and $\mathrm{Xu}$ (2003)}

Bansal and $\mathrm{Xu}$ (2003) have numerically investigated the effect of subcooling for a lateral capillary-tube/suction-line heat exchanger working with R-134a. The following geometrical conditions were considered: total length $1.9 \mathrm{~m}$, inlet adiabatic section length $0.7 \mathrm{~m}$, heat exchanger length $1 \mathrm{~m}$, capillary tube inner diameter $0.66 \mathrm{~mm}$, wall roughness $0.46 \mu \mathrm{m}$, and suction line internal diameter $6.6 \mathrm{~mm}$. The operating conditions were: condensing temperature $34.95{ }^{\circ} \mathrm{C}$, evaporating temperature $-15{ }^{\circ} \mathrm{C}$, superheating degree at suction line inlet $2{ }^{\circ} \mathrm{C}$ and subcooling degree ranging from 1 to $3{ }^{\circ} \mathrm{C}$.

15 Numerical convergence difficulties were encountered by Bansal and $\mathrm{Xu}$ (2003) as the inlet subcooling was increased further than $3.5^{\circ} \mathrm{C}$. The authors realized that these problems were related to the fact that the refrigerant re-condensed 
within the heat exchanger section and then entered the outlet adiabatic section as subcooled liquid. The outlet adiabatic section was not long enough $(0.2 \mathrm{~m})$ to reach the critical state (they noticed that for longer outlet sections, such as $0.3 \mathrm{~m}$, the convergence problem disappeared).
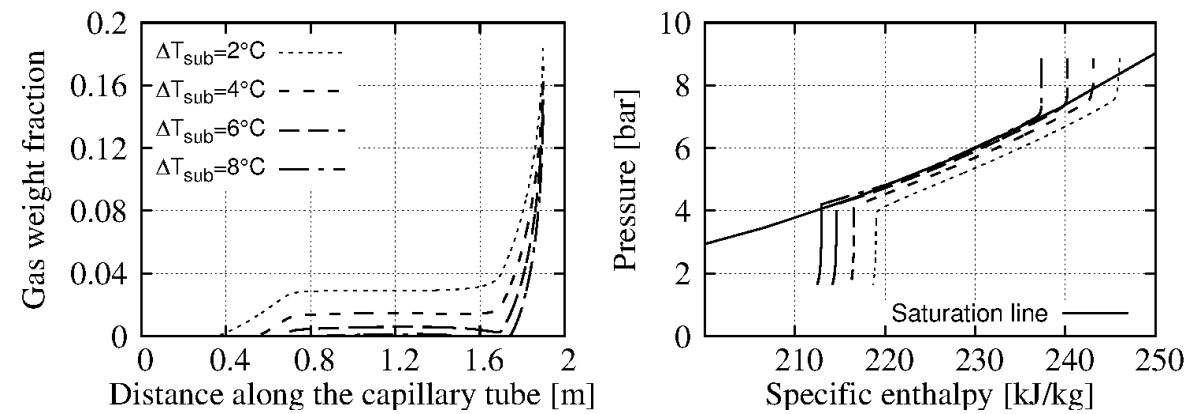

Figure 14: Present numerical model simulations of numerical cases from Bansal and Xu (2003).

Figure 14 shows the numerical results obtained with the present model considering the same geometric and operating conditions of Bansal and $\mathrm{Xu}$ (2003). The subcooling has been varied from 1 to $8{ }^{\circ} \mathrm{C}$ with a step of $0.5{ }^{\circ} \mathrm{C}$ (only 4 cases are presented in the figure for clarity purposes). Convergence has been achieved in the whole range of the studied cases. For the cases below a subcooling of $6{ }^{\circ} \mathrm{C}$ the refrigerant attains a higher gas weight fraction in the inlet adiabatic section. Therefore, the re-condensation phenomenon is not strong enough to drive the refrigerant to the liquid phase. On the contrary, for the cases above that subcooling value, the liquid phase re-appears in the capillary tube. Despite the shortness of the outlet adiabatic part of the lateral capillary-tube/suctionline heat exchanger the critical state is calculated satisfactorily with the present model.

\subsection{Experimental Cases}

Few experimental tests with possible numerical convergence instabilities were found among the data set collection presented in Table 1. None of them was found to be as demanding in terms of convergence as the numerical cases stud- 
ied in the previous sections. However, some cases are likely to have convergence issues when simulated numerically as they exhibit refrigerant pressure slopes almost superposed to saturation lines together with relatively short outlet adiabatic sections. The numerical results of two particular experimental cases are 5 plotted in Figure 15. In both cases the pressure profiles evolve in the vicinity of the saturation line. The predicted mass flow rates for the cases of Greenfield and Dunn (1994) and Khan et al. (2009b) are 5.46 and $7.29 \mathrm{~kg} \mathrm{~h}^{-1}$, while the experimental values are 5.79 and $7.6 \mathrm{~kg} \mathrm{~h}^{-1}$, respectively.

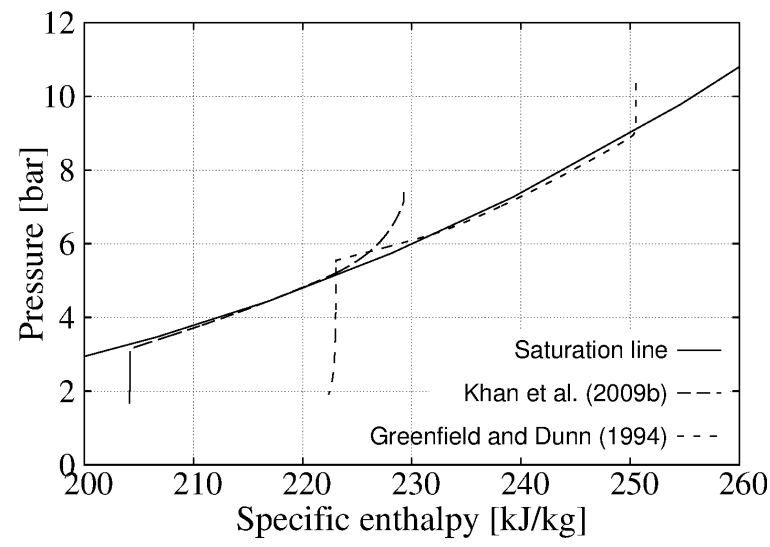

Figure 15: Model numerical results for two illustrative cases: Greenfield and Dunn (1994) (D $=0.78 \mathrm{~mm}, \mathrm{D}_{\text {suc }}=7.94 \mathrm{~mm}, \mathrm{p}_{\text {cond }}=8.17 \mathrm{bar}, \Delta \mathrm{T}_{\text {sub }}=2.78^{\circ} \mathrm{C}, \mathrm{p}_{\text {evap }}=1.32 \mathrm{bar}, \mathrm{T}_{\text {suc }, \text { in }}$ $=-15.16^{\circ} \mathrm{C}$ ) and Khan et al. (2009b) $\left(\mathrm{D}=1.12 \mathrm{~mm}, \mathrm{D}_{\text {suc }}=6.35 \mathrm{~mm}, \mathrm{p}_{\text {cond }}=7.39\right.$ bar, $\Delta \mathrm{T}_{\text {sub }}=7.3^{\circ} \mathrm{C}, \mathrm{p}_{\text {evap }}=1.67$ bar, $\left.\mathrm{T}_{\text {suc }, \text { in }}=-7.45^{\circ} \mathrm{C}\right)$.

\section{Numerical Studies}

In this section the numerical model is used to analyze different aspects of the capillary-tube/suction-line heat exchanger behaviour. Firstly, the influence of the model input variables over the dependent variables is investigated. Secondly, the influence of the capillary tube geometric arrangement type is studied, And thirdly, the heat flux profiles of the collected experimental data are also analyzed. 


\subsection{Influence of Input Parameters}
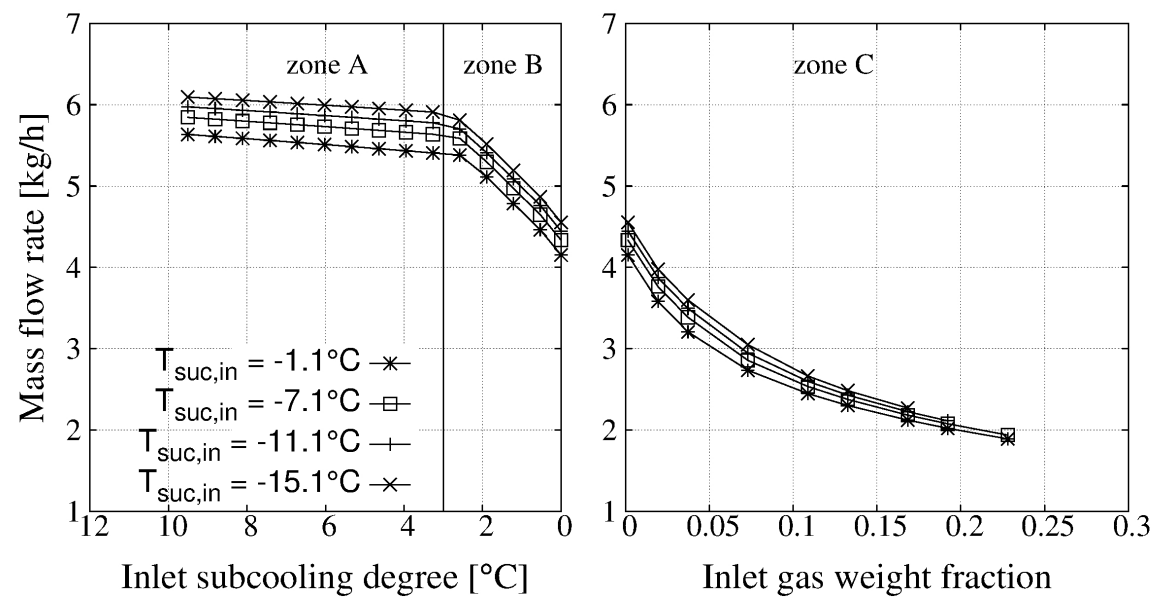

Figure 16: Capillary tube mass flow rate calculated at different inlet subcooling degrees/qualities and suction line inlet temperatures.

The boundary conditions needed for the non-adiabatic capillary tube model include the condensing and the evaporating pressures, the capillary tube inlet enthalpy, and the suction line inlet temperature. If the capillary-tube/suctionline heat exchanger is assumed to work at critical conditions, the evaporating pressure has a minor effect on the global solution. In fact, the solution will basically depend on the capillary tube inlet state (pressure and enthalpy) and the suction line inlet temperature. In the present section a set of simulations is conducted to study the influence of those boundary parameters on the basis of the capillary tube geometry described in Figure 8. The results are shown in Figure 16 where the system mass flow rate is calculated for different suction line inlet temperatures and a wide range of inlet capillary tube enthalpies (ranging from a subcooling degree of $10{ }^{\circ} \mathrm{C}$ to a gas weight fraction of 0.25$)$. The system working pressures were kept constant.

The effect of the suction line inlet temperature is observed in Figure 16. For a particular inlet subcooling degree (or inlet gas weight fraction) the refrigerant mass flow rate increases as the suction line inlet temperature decreases. The 
heat transferred inside the capillary tube augments due to the increase of the temperature gradient between the capillary tube and the suction line flows. Therefore, as shown in Figure 17 (the numbering is equivalent to that of Figure 8), the single-phase region (1-2-3-3') is extended while the two-phase region 5 in the outlet adiabatic section (3'-4) is shortened. As a result, the refrigerant pressure drop through the capillary tube is slightly reduced and the mass flow rate is increased.

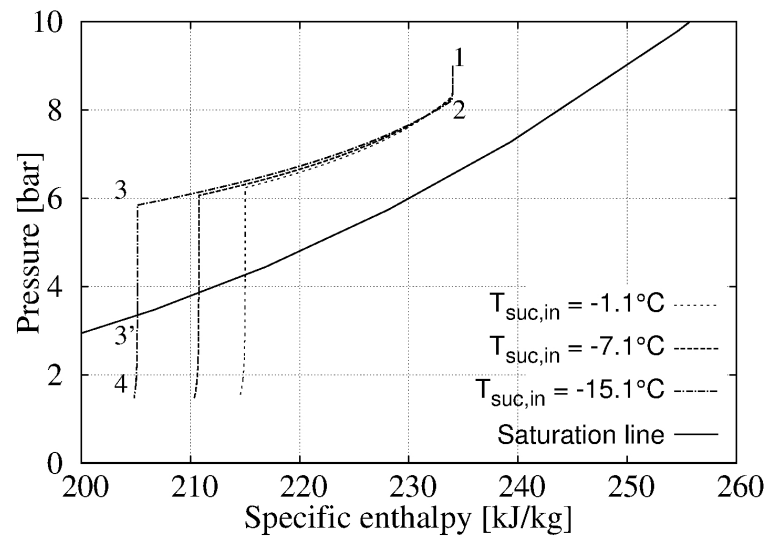

Figure 17: Pressure vs. enthalpy diagram: influence of suction line inlet temperature.

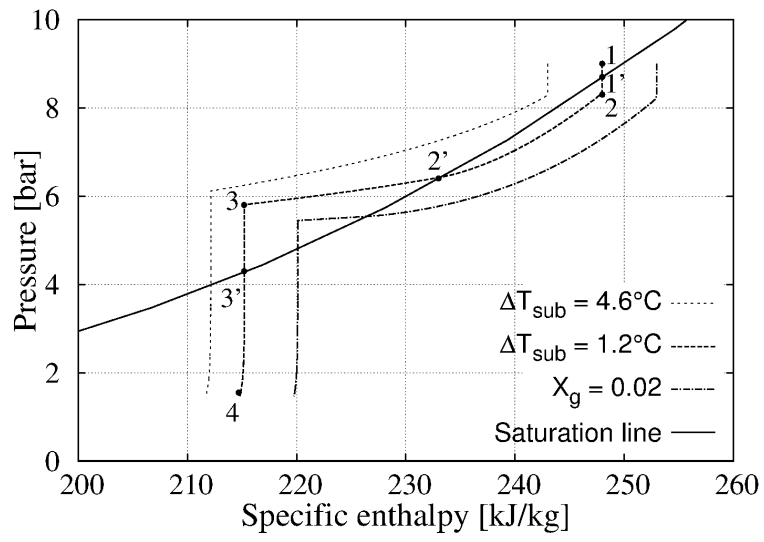

Figure 18: Pressure vs. enthalpy diagram: influence of capillary tube refrigerant inlet state. 
The effect of the refrigerant inlet state is also observed in Figure 16. The capillary-tube/suction-line mass flow rate decreases as the inlet capillary tube enthalpy increases, i.e., as the subcooling degree decreases or as the gas weight fraction increases. Three different zones are observed. Zone A: for subcooling values greater than $3{ }^{\circ} \mathrm{C}$ the mass flow rate varies linearly with a gentle slope. Zone B: between $3{ }^{\circ} \mathrm{C}$ of subcooling and the saturation limit, the mass flow rate variation is also linear but with a steeper slope. And zone C: from the saturation limit and beyond, the mass flow rate value decreases exponentially as the inlet quality increases. This behaviour could be understood from Figure 18. In zone $\mathrm{A}$ (subcooling of $4.6^{\circ} \mathrm{C}$ ), the refrigerant flow inside the first two sections of the capillary tube remains in single-phase condition (1-3). If the inlet enthalpy is modified, the pressure drop and the resulting mass flow rate will vary gently. In zone $\mathrm{B}$ (subcooling of $1.2^{\circ} \mathrm{C}$ ), the refrigerant reaches the two-phase state within the first section of the capillary tube (1-2) at position

15 (1'). The flow will be re-condensated until position (2'). The pressure drop through the two-phase region (1'-2') will increase resulting on smaller mass flow rate. The two-phase flow zone (1'-2') will rapidly grow as the inlet enthalpy increases. In zone $\mathrm{C}$ (gas weight fraction of 0.02 ) the refrigerant state at the inlet is two-phase. This state remains throughout the whole inlet adiabatic 20 section (1-2) and troughout all - or part of - the heat exchanger section (1-2'). As the inlet gas weight fraction increases, the single-phase region at the end of the heat exchange section decreases progressively entailing an increase of the overall flow resistance so that the calculated mass flow rate decreases in a similar way.

${ }_{25}$ For the particular capillary tube geometry studied herein, zone B relative size will depend on the inlet adiabatic section length. In this case, it is worth mentioning that for a small range of inlet enthalpies, i.e. from $3{ }^{\circ} \mathrm{C}$ of subcooling to an inlet gas weight fraction of 0.1 , the system mass flow rate could present large variations (almost $3 \mathrm{~kg} \mathrm{~h}^{-1}$ ), whereas out of this range the variations are

so lower. This aspect could play an important role when studying the capillary tube as a refrigeration system mass flow rate control device. If there were no 
inlet adiabatic section, no zone B would be present.

\subsection{Lateral vs. Concentric Configuration}

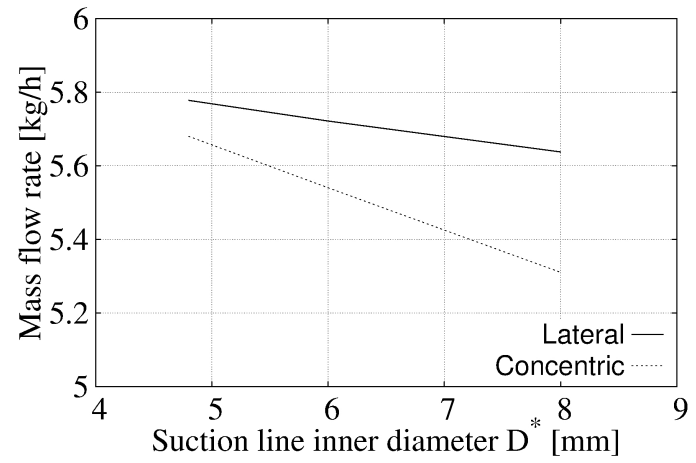

Figure 19: Predicted mass flow rate as a function of the suction line diameter for both capillary tube configurations.

The influence of the capillary tube arrangement type is numerically studied for the case reported in the previous section. Figure 19 shows the mass flow rate calculated for the two studied capillary tube arrangements as a function of the suction line inner diameter (the selected case corresponds to a subcooling degree of $3.2{ }^{\circ} \mathrm{C}$ ). The suction line inner diameter of the lateral configuration is chosen as the reference value $\left(\mathrm{D}^{*}\right)$ while the corresponding suction line inlet diameter used in the concentric arrangement was deduced by keeping the same cross-sectional area. The Figure shows that, for relatively small suction line diameters, the mass flow rates calculated with both configurations are similar. However, if the suction line diameter is increased the lateral arrangement produces greater mass flow rate values compared to the concentric configuration. This behaviour may be explained from the lateral configuration nature where the whole solid arrangement acts as a fin, whereas the heat transfer area of the suction line in the concentric configuration is limited to the capillary tube outer diameter. Similar conclusions were drawn by Peixoto and Bullard (1994). It is worth mentioning that the solid part in the lateral configuration is represented 
by a one-dimensional sequence of control volumes where each has a unique temperature associated. Therefore, the fin effect could be overestimated by the model. However, according to a simplified analytical study of the suction line solid in the experimental cases with lateral arrangement, the fin efficiencies are 5 sufficiently high to support the unique temperature hypothesis.

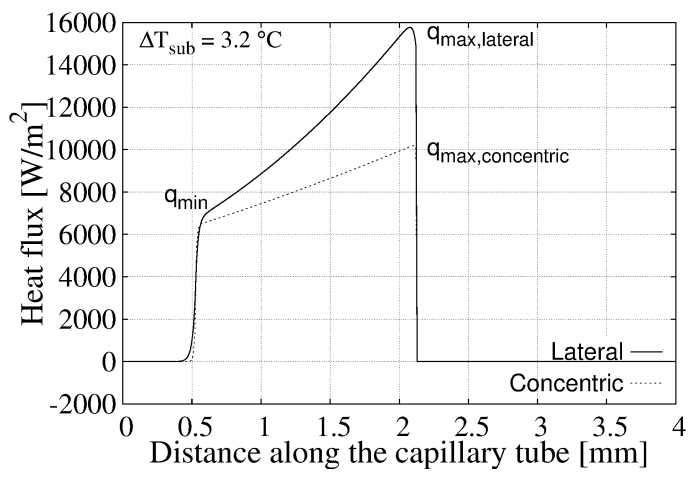

Figure 20: Heat flux evolution along capillary tubes: lateral and concentric arrangement.

Figure 20 presents the heat flux profile comparison between lateral and concentric configurations for the particular case with a suction line inner diameter of $8 \mathrm{~mm}$ in order to have a better insight of the heat transfer phenomenon. The lateral configuration performs better than the concentric one as it has a lower overall thermal resistance due to a larger heat transfer area between the capillary tube solid part and the suction line fluid (the mass flow rate increases as the heat transfer increases). The heat flux profile is not uniform, but instead varies almost linearly along the heat exchange section of the capillary tube. The heat flux slope in the lateral configuration is highly dependent on the suction line inner diameter.

Figure 21 compares the performance of the lateral and concentric arrangement types for a wide range of inlet subcooling degrees and gas weight fractions. It is observed that significant differences of mass flow rate values are obtained on the Zone A (when the refrigerant flowing throughout the first and second sections remains in single-phase state). However, this difference is reduced in- 
side the Zones $\mathrm{B}$ and $\mathrm{C}$. The reason is that, in Zone $\mathrm{A}$, the variation of the capillary tube refrigerant temperature inside the heat exchanger is directly related to the heat exchange with the suction line fluid, while in the other zones, the refrigerant temperature change is also affected by the rapid pressure drop 5 during two-phase state (thus reducing the heat exchanger temperature gradient and the overall heat transfer). The heat exchanged profile is shown in Figure 22 .
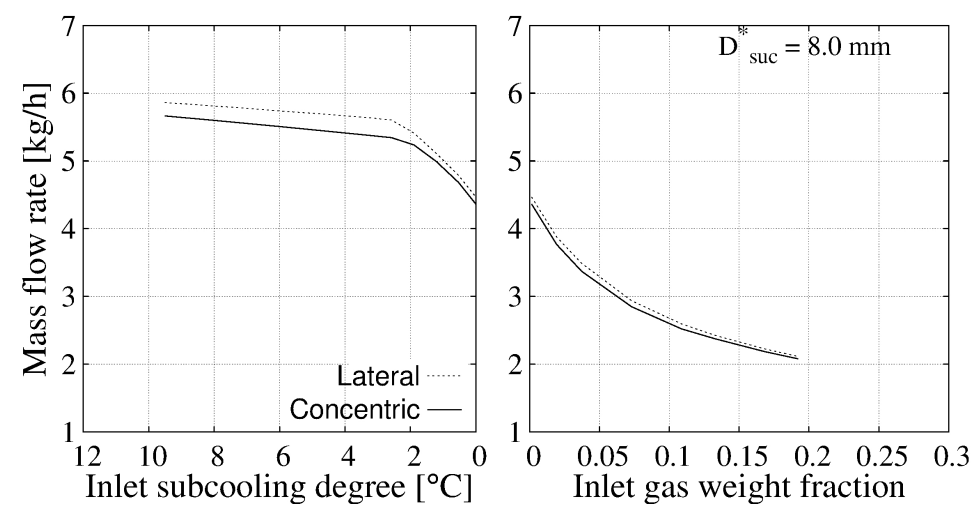

Figure 21: Capillary tube mass flow rate calculated at different inlet subcooling degrees/qualities (lateral vs. concentric arrangement).
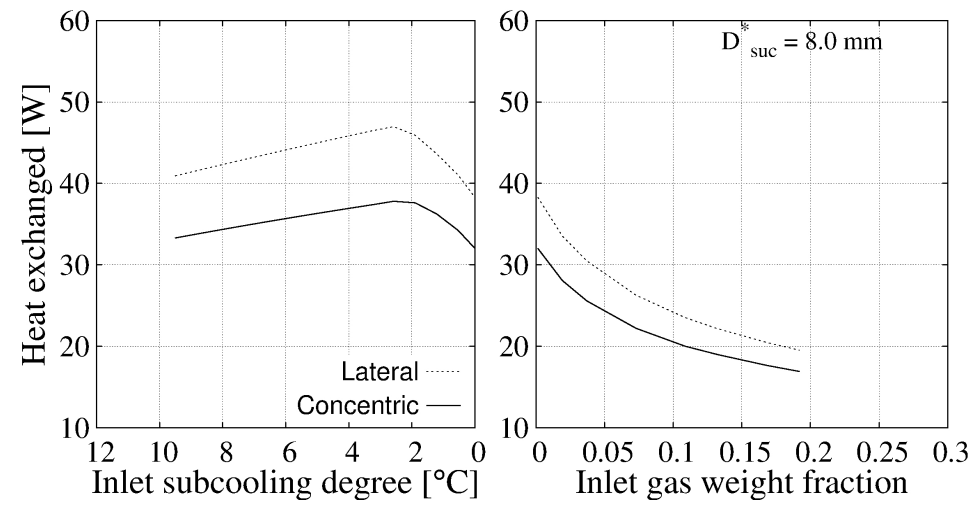

Figure 22: Capillary tube exchanged heat at different inlet subcooling degrees/qualities (lateral vs. concentric arrangement). 


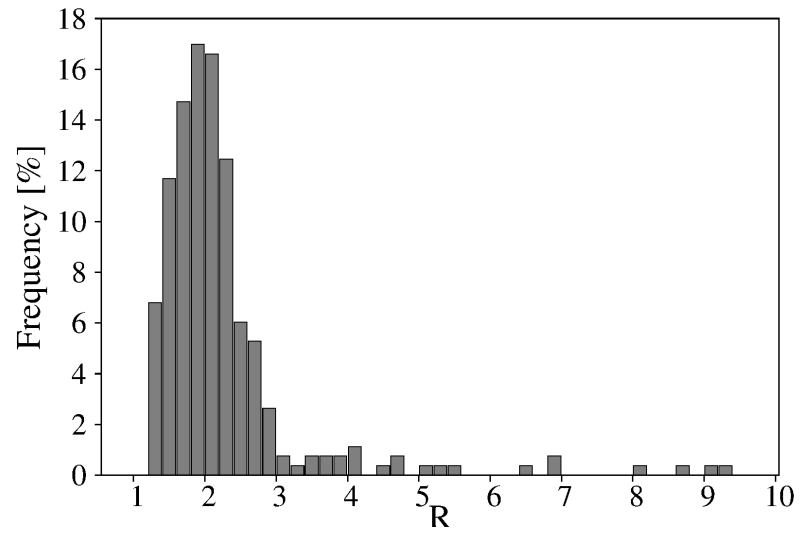

Figure 23: Value of $\mathrm{R}$ calculated from the numerical predictions of the 278 experimental cases reported in Table 1

\subsection{Heat Transfer Analysis}

As shown in Figure 20, the heat flux profile along the capillary tube shows an approximate linear behaviour that goes from a minimum value $\left(\dot{q}_{\min }\right)$ to a maximum one $\left(\dot{q}_{\max }\right)$. The quotient of $\dot{q}_{\max }$ divided by $\dot{q}_{\min }$ is defined as $R$ and

5 gives us an idea of how uniform is the heat flux distribution along the capillary tube. This value has been calculated for all the cases reported in Table 1 and the results are plotted in Figure 23 .

Most of the cases have an $R$ between 1.2 and 3. The value of $R$ is close to the unity when the exchange section is relatively short, and similarly, the value is greater than 3 when the exchange section is relatively long. Figure 24 shows the heat flux profiles for capillary tubes with differents values of $R$. The cases with longer heat exchange sections - and higher value of $R$ - present exponential profiles rather than linear ones. This study illustrates the non-uniformity of the heat flux distribution found in capillary-tube/suction-line heat exchangers.

\section{Conclusions}

In this work a detailed distributed model for capillary-tube/suction-line heat exchangers was described and comprehensively validated. A large number of 


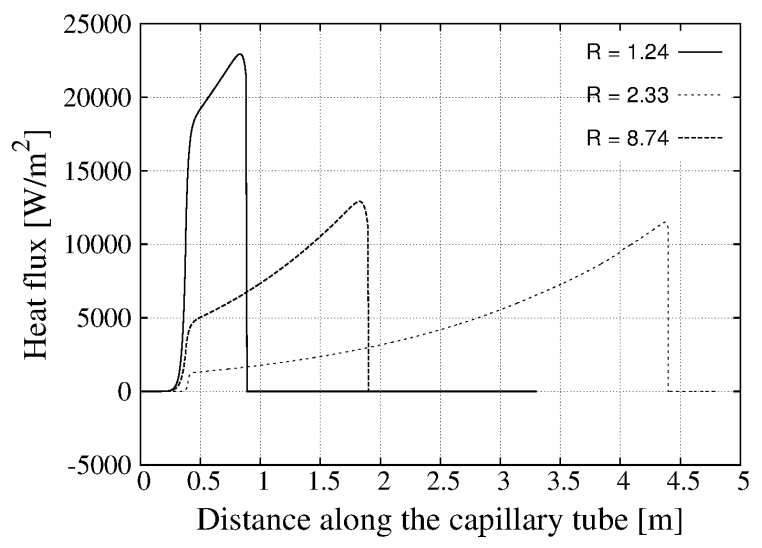

Figure 24: Heat flux profiles for three selected cases with different values of $R$.

experimental cases found in the technical literature were reproduced with the proposed numerical model in order to show its reliability. Two typically used geometric arrangements were considered (i.e. lateral and concentric) for different refrigerants and a wide range of operating and geometric characteristics.

5 The overall mass flow rate mean prediction deviation was $8.1 \%$ and the overall mean relative temperature deviation was $4.4 \%$.

The model convergence issues present in the near-saturation zone were carefully addressed leading to the implementation of several numerical modifications. The model has greatly improved its convergence capabilities and proved to be successful when tackling cases where high convergence difficulties were reported by other distributed models found in the technical literature. The importance of having stable and robust convergence in the aforementioned zone was highlighted.

The enhanced model was used to carry out parametric studies on non-adiabatic 15 capillary tubes to provide a better insight on the thermal and fluid-dyamnic behaviour of such expansion devices. The influence of both the capillary tube inlet operating parameters and its geometric arrangement was studied. In addition, an analysis of the heat transfer occurring within the non-adiabatic section of the capillary tube was carried out. 


\section{Nomenclature}

$D \quad$ diameter, $m$

$e \quad$ specific energy, $\mathrm{Jkg}^{-1<}$

$g$ acceleration due to gravity, $\mathrm{ms}^{-2}$

$5 \quad h$ enthalpy, $J k^{-1}$

$L \quad$ length, $m$

$\dot{m}$ mass flow rate, $\mathrm{kg} \mathrm{s}^{-1}$

$N$ number of points

$p$ pressure, $\mathrm{Pa}$

${ }_{10} \quad \dot{q}$ heat flux, $W m^{-2}$

$S$ cross section, $m^{2}$

$T$ temperature, ${ }^{\circ} \mathrm{C}$

$v$ velocity, $m s^{-1}$

$x_{g}$ gas weight fraction

15 Greek symbols

$\Delta z \quad$ axial step, $m$

$\epsilon$ roughness, $\mu m$

$\Theta$ angle, $r a d$

$\rho$ density, $\mathrm{kg} \mathrm{m}^{-3}$

${ }_{20} \tau$ shear stress, $\mathrm{Pa}$

$\phi$ variable

\section{Subscripts}

c kinetic

calc calculated

${ }_{25} \mathrm{cv}$ control volume

exp experimental

IHE non-adiabatic section

$i$ grid position

in inlet

30 out outlet 
$p$ potential

sub subcooling

suc suction line

\section{Superscripts}

5 guessed value

- average value

\section{Acknowledgements}

This work has been partially developed within the research project Numerical simulation and experimental validation of liquid-vapour phase change phenomena. Application to thermal systems and equipments-II (ENE2011-28699) of the Spanish Government, and the project INNPACTO KERS (IPT-020002010-30) between the company Fagor Electrodomsticos, S. Coop. and the ¿CTTC. The detailed information of the experimental tests obtained from Khan

15 et al. (2009b) were kindly provided by the corresponding authors.

\section{References}

N. Ablanque. Numerical Simulation and Experimental Validation of Vapor Compression Refrigerating Systems. Special Emphasis on Natural Refrigerants. PhD thesis, Universitat Politcnica de Catalunya, 2010.

20 N. Ablanque, J. Rigola, C.D. Pérez-Segarra, and A. Oliva. Numerical simulation of capillary tubes. Application to domestic refrigeration with isobutane. In Proceedings of the International Refrigeration and Air Conditioning Conference at Purdue, 2010.

N. Ablanque, C. Oliet, J. Rigola, and C.D. Pérez-Segarra. Numerical model of capillary tubes: Enhanced performance and study of non-adiabatic effects. In Proceedings of the International Refrigeration and Air Conditioning Conference at Purdue, 2014. 
P.K. Bansal and B. Xu. A parametric study of refrigerant flow in non-adiabatic capillary tubes. Applied Thermal Engineering, 23(4):397-408, 2003.

P.K. Bansal and C. Yang. Reverse heat transfer and re-condensation phenomena in non-adiabatic capillary tubes. Applied Thermal Engineering, 25(17-18):

$5 \quad 3187-3202,2005$.

Z. H. Chen, R. Y. Li, S. Lin, and Z. Y. Chen. A correlation for metastable flow of refrigerant 12 through capillary tubes. ASHRAE Transactions, 96(1): $550-554,1990$.

S. W. Churchill. Frictional equation spans all fluid flow regimes. Chemical Engineering, 84(24):91-92, 1977.

E. Dirik, C. Inan, and M.Y. Tanes. Numerical and experimental studies on adiabatic and nonadiabatic capillary tubes with HFC-134a. In Proceedings of the International Refrigeration and Air Conditioning Conference at Purdue, 1994.

F. Escanes, C. D. Pérez-Segarra, and A. Oliva. Numerical simulation of capillary tube expansion devices. International Journal of Refrigeration, 18(2):113$122,1995$.

L. Friedel. Improved friction pressure drop correlation for horizontal and vertical two-phase pipe flow. In Proceedings of the European Two-Phase Flow Group Meeting, 1979.

O. García-Valladares. Numerical simulation of non-adiabatic capillary tubes considering metastable region. Part II: Experimental validation. International Journal of Refrigeration, 30:654-663, 2007.

O. García-Valladares, C.D. Pérez-Segarra, and Oliva A. Numerical simulation of capillary tube expansion devices behaviour with pure and mixed refrigerants considering metastable region. Part i: mathematical formulation and numerical model. Applied Thermal Engineering, 22(2):173-182, 2002a. 
O. García-Valladares, C.D. Pérez-Segarra, and Oliva A. Numerical simulation of capillary tube expansion devices behaviour with pure and mixed refrigerants considering metastable region. Part ii: experimental validation and parametric studies. Applied Thermal Engineering, 22(4):379-391, 2002b.

5 V. Gnielinski. New equations for heat and mass transfer in turbulent pipe and channel flow. International Chemical Engineering, 16(2):359-368, 1976.

K.P. Greenfield and W.E. Dunn. Experimental study of non-adiabatic flow of refrigerant R-134a in a capillary tube. Technical report, Air Conditioning and Refrigeration Center, University of Illinois, 1994.

10 K. E. Gungor and R. H. S. Winterton. Simplified general correlation for saturated flow boiling and comparisons of correlations with data. Chemical Engineering Research and Design, 65(2):148-156, 1987.

C.J.L. Hermes, C. Melo, and J.M. Gonalves. Modeling of non-adiabatic capillary tube flows: A simplified approach and comprehensive experimental validation.

15 International Journal of Refrigeration, 31:1358-1367, 2008.

M.K. Khan, R. Kumar, and P.K. Sahoo. Flow characteristics of refrigerants flowing through capillary tubes - A review. Applied Thermal Engineering, 29 (8-9):1426-1439, 2009a.

M.K. Khan, R. Kumar, and P.K. Sahoo. Experimental investigation on the flow of R134a through adiabatic and diabatic capillary tubes. ASHRAE Transactions, 115:82-92, 2009b.

C. Melo, C.B. Neto, and R.T.S. Ferreira. Empirical correlations for the modeling of R-134a flow through adiabatic capillary tubes. ASHRAE Transactions, 105 (2):51-60, 1999 .

${ }_{25}$ C. Melo, J.M. Zangari, R.T.S. Ferreira, and R.H. Pereira. Experimental studies on non-adiabatic flow of HFC-134a through capillary tubes. In Proceedings of the International Refrigeration and Air Conditioning Conference at Purdue, 2000. 
C. Melo, L. A. Torquato, and R. Horn. Non-adiabatic capillary tube flow with isobutane. Applied Thermal Engineering, 22(14):1661-1672, 2002.

K.C. Mendonça, C. Melo, R.T.S. Ferreira, and R.H. Pereira. Experimental study on lateral capillary tube-suction line heat exchangers. In Proceedings of

5 the International Refrigeration and Air Conditioning Conference at Purdue, 1998.

C.O.R. Negrão and C. Melo. Shortcomings of the numerical modeling of capillary tube-suction line heat exchangers. In Proceedings of the International Congress of Refrigeration, number 1-7, 1999.

NIST. Thermodynamic properties of refrigerants and refrigerant mixtures database (REFPROP). Version 7.0, 2002.

R.A. Peixoto. Experimental analysis and numerical simulation of capillary tubesuction line heat exchanger using refrigerant HFC-134a. In Proceedings of the 1995 International Congress of Refrigeration at The Hague, 1995.

R.A. Peixoto and C.W. Bullard. A simulation and design model for capillary tube-suction line heat exchangers. In Proceedings of the International Refrigeration and Air Conditioning Conference at Purdue, 1994.

A. Premoli, D. Francesco, and A. Prima. An empirical correlation for evaluating two-phase mixture density under adiabatic conditions. In Proceedings of the European Two-Phase Flow Group Meeting, 1970.

H. Qiao, R. Radermacher, and V. Aute. A review for numerical simulation of vapor compression systems. In Proceedings of the International Refrigeration and Air Conditioning Conference at Purdue, 2010.

D. Sarker and J.H. Jeong. Development of empirical correlations for nonadiabatic capillary tube based on mechanistic model. International Journal of Refrigeration, 35(4):974-983, 2012. 
M. M. Shah. A general correlation for heat transfer during film condensation inside pipes. International Journal of Heat and Mass Transfer, 22(4):547-556, 1979.

J.H. Wiegand, E.L. McMillen, and Larson H.E. Discussion on: annular heat transfer coefficients for turbulent flow. American Institute of Chemical Engineers, 41:147-153, 1945.

D.A. Wolf and M.B. Pate. Capillary tube-suction line heat exchanger performance with alternative refrigerants, ASHRAE report 928RP. Technical report, 2002. 


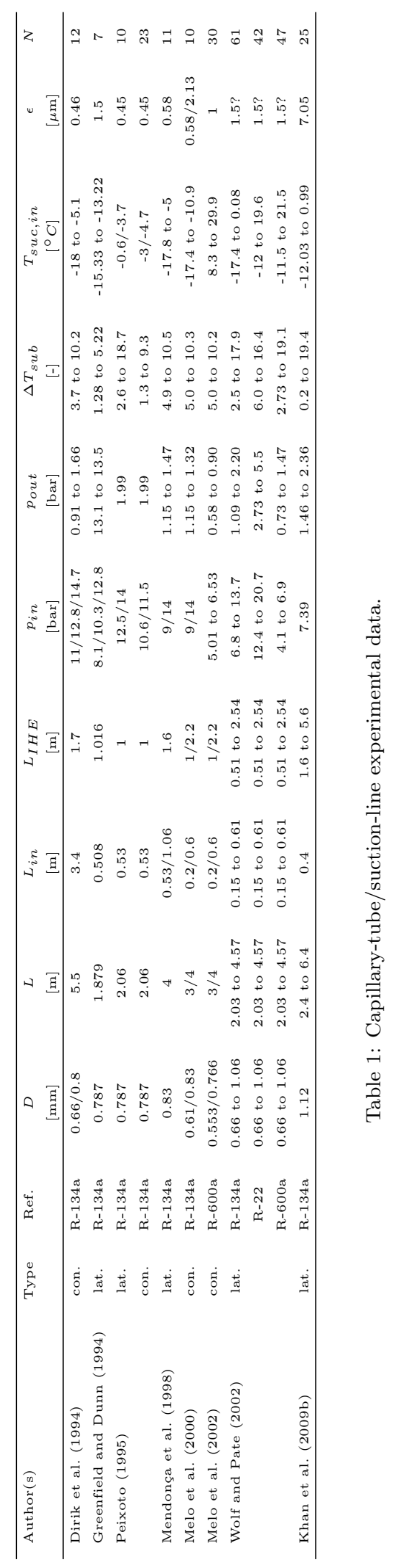

